\title{
Molecular phylogeny of the heterocystous cyanobacteria (subsections IV and V) based on nifD
}

\author{
Brian J. Henson, Sharon M. Hesselbrock, Linda E. Watson \\ and Susan R. Barnum
}

Correspondence

Susan R. Barnum

Department of Botany, Miami University, Oxford, OH 45056, USA

barnumsr@muohio.edu

\begin{abstract}
The heterocystous cyanobacteria are currently placed in subsections IV and V, which are distinguished by cellular division in one plane (false branching) and in more than one plane (true branching), respectively. Published phylogenies of $16 \mathrm{~S}$ rRNA gene sequence data support the monophyly of the heterocystous cyanobacteria, with members of subsection $V$ embedded within subsection IV. It has been postulated that members of subsection $V$ arose from within subsection IV. Therefore, phylogenetic analysis of nucleotide sequences of the nitrogen-fixation gene nifD from representatives of subsections IV and V was performed by using maximum-likelihood criteria. The heterocystous cyanobacteria are supported as being monophyletic, with the non-heterocystous cyanobacteria as their closest relative. However, neither subsection IV nor subsection $\mathrm{V}$ is monophyletic, with representatives of both subsections intermixed in two sister clades. Analysis of nifD does not support recognition of two distinct subsections.
\end{abstract}

Cyanobacteria are oxygenic, photosynthetic prokaryotes that can be found in almost every aquatic and terrestrial environment (Castenholz \& Waterbury, 1989) and are ancient organisms that date back $3 \cdot 5$ billion years in the fossil record (Castenholz, 1992). It has been proposed that cyanobacteria were responsible for converting the ancient Earth's anaerobic atmosphere to an aerobic one (Hayes, 1983; Schopf et al., 1983). Many cyanobacteria fix nitrogen (diazotrophy) and they comprise one of the largest global suppliers of fixed nitrogen in the environment (Sprent \& Sprent, 1990). In addition, some species of nitrogen-fixing cyanobacteria are involved in symbiotic relationships with many plant species and supply the host directly with a source of reduced nitrogen.

The taxonomy of the cyanobacteria has been debated vigorously and revised many times (Golubic, 1976; Turner, 1997). The cyanobacteria have been reclassified by using bacteriological instead of botanical criteria, based on morphological and developmental features, but most species, including those used in this study, have not yet been given validly published names under the Bacteriological Code. Cyanobacteria are currently divided into five subsections (Rippka

Published online ahead of print on 31 October 2003 as DOI 10.1099/ ijs.0.02821-0.

The GenBank/EMBL/DDBJ accession numbers for nifD sequences determined in this study are AY196951-AY196958.

A table showing the current taxonomic placement of the heterocystous cyanobacteria and an alignment of nifD gene sequences are available as supplementary material in IJSEM Online. et al., 1979; Rippka, 1988; Castenholz \& Waterbury, 1989; Castenholz, 1992, 2001; Rippka \& Herdman, 1992). Subsection I strains are unicellular and divide by binary fission or budding (Rippka et al., 1979). Subsection II strains are also unicellular but divide by multiple fission, resulting in the formation of baeocytes (Rippka et al., 1979; Rippka, 1988; Castenholz \& Waterbury, 1989; Castenholz, 1992, 2001; Rippka \& Herdman, 1992). Subsection III strains are filamentous, non-heterocystous cyanobacteria that reproduce by trichome breakage (Rippka et al., 1979; Rippka, 1988; Castenholz \& Waterbury, 1989; Castenholz, 1992, 2001; Rippka \& Herdman, 1992). Subsections IV and V are composed exclusively of heterocystous cyanobacteria, which are filamentous strains that reproduce by hormogonia formation and have the ability to develop heterocysts and akinetes (Rippka et al., 1979; Rippka, 1988; Castenholz \& Waterbury, 1989; Castenholz, 1992, 2001; Rippka \& Herdman, 1992; Hoffman \& Castenholz, 2001). The heterocystous cyanobacteria are placed into subsections IV and V, based on their ability to divide in one (false branching) or more than one (true branching) plane, respectively (Rippka et al., 1979; Rippka, 1988; Castenholz \& Waterbury, 1989; Castenholz, 1992, 2001; Rippka \& Herdman, 1992; Hoffman \& Castenholz, 2001). Subsection IV is divided further into two subgroups: subsection IV.I, which is composed of strains that do not show basal-apical polarity of their trichomes, and subsection IV.II, which is composed of strains that show distinct basal-apical polarity of their trichomes, with the trichomes tapering from the apex to the base (Castenholz, 2001; Rippka et al., 2001). A table 
showing the current taxonomic placement of the heterocystous cyanobacteria into subsections IV.I, IV.II and V is available as supplementary material in IJSEM Online.

It has been postulated that some of the morphological characters that are used to delineate the cyanobacteria may not reflect true evolutionary relationships within the lineage (Mollenhauer, 1988; Rippka, 1988; Rippka \& Herdman, 1992). Molecular phylogenies have been employed to resolve evolutionary relationships within the cyanobacteria. In general, molecular phylogenies support the monophyly of subsections II, IV and V, whereas subsections I and III are not supported as being monophyletic (Giovannoni et al., 1988; Wilmotte, 1994; Turner, 1997; Zehr et al., 1998, 2000; Turner et al., 1999). 16S rRNA phylogenies support the monophyly of the heterocystous cyanobacteria and place subsection $\mathrm{V}$ within subsection IV, suggesting that the former arose from within the latter. Analysis of partial nifH sequences also supports the monophyly of the heterocystous cyanobacteria as a whole, but with members of subsections IV and V intermixed (Zehr et al., 1998, 2000).

Our objective was to examine whether or not phylogenetic analysis of nifD supports the division of the heterocystous cyanobacteria into subsections IV and V. We examined phylogenetic relationships within the heterocystous cyanobacteria by analysing nifD nucleic acid sequences from representatives of subsections IV and V. nifD was chosen as previous studies have indicated that its divergence is intermediate between that of nifH and nifK (Mathur \& Tuli, 1990) and should thus provide sufficient phylogenetic signal to resolve relationships within and among subsections IV and V. Furthermore, previous studies in our laboratory have shown that nifD is a good marker for resolving relationships within the heterocystous lineage (Henson et al., 2002). It has been questioned whether nif genes have evolved by lateral transfer or vertical descent, which could affect our analyses, but recent evidence suggests that nifD evolved by vertical descent (Henson et al., 2004). We analysed orthologous nifD genes that belong to the nif1 operon, excluding the alternative nitrogenases anfD, vnfD and nifD2. To ensure that the heterocystous cyanobacterial sequences were nifD1 sequences and not nifD2 sequences, we included the nifD2 sequence from Anabaena variabilis (Thiel, 1993) in some of our analyses. All analyses that included the nifD2 sequence placed it outside the heterocystous cyanobacteria, with the non-heterocystous cyanobacteria (data not shown).

Heterocystous cyanobacteria examined were obtained from the Pasteur Culture Collection (PCC) and the University of Texas culture collection (UTEX). Cultures were grown in illuminated shaking incubators at $27^{\circ} \mathrm{C}$, in BG- $11_{0}+\mathrm{NaHCO}_{3}$ $(5 \mathrm{mM})$ and BG-11 ${ }_{0}+\mathrm{NaNO}_{3}(2 \mathrm{mM})+\mathrm{NaHCO}_{3}(10 \mathrm{mM})$ media (Rippka et al., 1979; Rippka \& Herdman, 1992). Cultures were checked regularly for bacterial contamination by plating on Luria broth (LB) solidified medium and incubating overnight at $37^{\circ} \mathrm{C}$.

Genomic DNA was extracted by using a Purgene DNA
Isolation kit (Gentra Systems), with slight modification. Amplification of nifD was accomplished by using the Expand Long Template PCR system (Roche). The PCR primers used to amplify nifD were $5^{\prime}$-GATGGCGATGTATGCTGCTAACAAC-3' (corresponding to nucleotide positions 474-499 of nifH) and 5'-GtACGGAAGTAAGCAACGCAACCTTG-3' (corresponding to nucleotide positions 277-302 of nifK). PCR products were verified by agarose gel electrophoresis and purified with a QIAquick Gel Extraction kit (Qiagen). PCR products were cloned by using a TOPO TA Cloning kit for sequencing (Invitrogen). Sequencing was accomplished with a BigDye Terminator Cycle Sequencing Ready Reaction kit (PE Biosystems) and a DYEnamic ET terminator cycle sequencing kit (Amersham Biosciences), using capillary electrophoresis on ABI 310 and ABI 3100 genetic analysers (Applied Biosystems). Both the forward and reverse strands of nifD were sequenced completely from one clone; the forward strand from an additional clone from each strain was sequenced to ensure that no PCR artefacts were present. Sequences were deposited in GenBank (accession numbers are listed in Fig. 1).

In addition to the nifD sequences generated in this study, other sequences were obtained from GenBank (accession numbers are listed in Fig. 1). Inferred amino acid sequences were aligned initially by using CLUSTAL W (Thompson et al., 1994), with gaps inserted for optimal alignment. The amino acid alignment was then adjusted visually by using MacClade 4.0 (Maddison \& Maddison, 2000). We compared our alignment visually to the PFAM alignment of nifD (http://pfam.wustl.edu/cgi-bin/getalignment), to ensure correct alignment. The nucleotide alignment was generated from the amino acid alignment by using Codon Align 1.0 (Barry Hall, University of Rochester). The alignment produced by Codon Align was inspected visually by using MacClade 4.0 (Maddison \& Maddison, 2000). A supplementary figure showing our nucleotide sequence alignment is available as supplementary material in IJSEM Online.

Analysis of the nucleic acid data matrix was performed by using maximum-likelihood criteria with PAUP* $4.0 \mathrm{~b} 10$ (Swofford, 2002). Prior to analysis, we determined the evolutionary model that best described our data by using MODELTEST 3.06 (Posada \& Crandall, 1998); the GTR + G model was determined to be the best fit for our data (likelihood score, $15973 \cdot 05941)$. Trees were rooted with outgroup analysis by using nifD sequences from four non-heterocystous cyanobacteria, six proteobacterial representatives and one actinobacterium (Frankia). Maximum-likelihood analysis was conducted by using the heuristic search option, with the likelihood settings corresponding to the GTR $+\mathrm{G}$ model as follows: no molecular clock was enforced; starting branchlengths were determined via the Rogers-Swofford approximation method; trees with likelihoods that were $\geqslant 5 \%$ from the target score were rejected; branch-length optimization equalled one-dimensional Newton Raphson with pass, where the limit $=20$ and $\delta=1 \mathrm{e}^{-06}$; starting trees were obtained via stepwise addition; sequence addition was random; one 


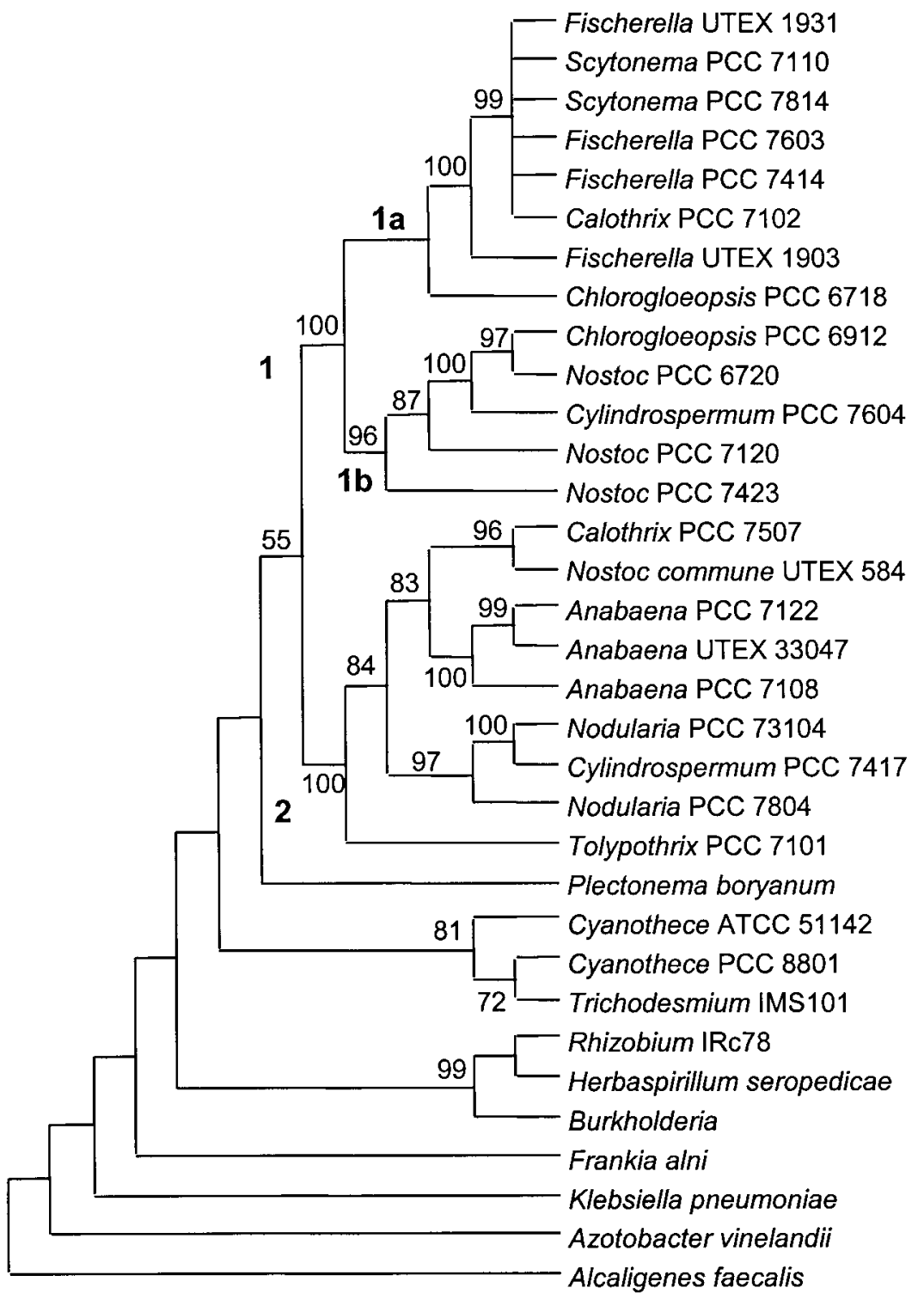

[V] U49514

[IV.I] AF442511

[IV.I] AY196954

[V] AY196958

[V] AF442512

[IV.II] AF442501

[V] AY196955

[V] AF442510

[V] AY196956

[IV.I] AF442502

[IV.I] AY196952

[IV.I] AF442504

[IV.I] AF442503

[IV.II] AY196951

[IV.I] L23514

[IV.I] AF442506

[IV.I] AF442507

[IV.I] AF442505

[IV.I] AF442509

[IV.I] AF442508

[IV.I] AY196957

[IV.II] AY196953

[III] D00666

[l] AF003337

[l] U22146

[III] AF016484

M10203

Z54207

AF194084

L41344

Y00316

X06886

$\times 95565$

Fig. 1. Maximum-likelihood tree of nifD nucleic acid sequences with a $-\ln \mathrm{L}$ score of $8850 \cdot 58935$. Cyanobacterial subgroups are shown in square brackets. Numbers above branches are bootstrap values. GenBank accession numbers are given on the right.

tree was held at each step during stepwise addition; the tree bisection-reconnection (TBR) branch-swapping algorithm was used; steepest descent option was not in effect; maxtrees was set to 50000 ; branches were collapsed if the branchlengths were $\leqslant 1 \mathrm{e}^{-08}$; the multrees option was in effect; and topological constraints were not enforced. Maximumlikelihood analysis was performed with the third codon position excluded and without. Bootstrap values were calculated for 1000 replicates to evaluate branch support by using parsimony criteria (Felsenstein, 1985; Bremer, 1994; Huelsenbeck et al., 1995). Parsimony and distance analyses of the data matrix were also performed.

Maximum-likelihood analysis generated a single tree with a $-\ln$ L score of $8850 \cdot 58935$ (Fig. 1). The heterocystous cyanobacteria are monophyletic, with the non-heterocystous cyanobacteria, proteobacteria and Frankia as sisters. Support for their monophyly is weak, with a bootstrap value of $55 \%$ (Fig. 1); however, this is consistent with analyses of nifH (Zehr et al., 1997, 1998, 2000). nifD does not support the monophyly of either subsection IV or subsection V. The heterocystous cyanobacteria occur in two major clades (1 and 2), with members of subsections IV and V intermixed.

Clade 1 is composed of two smaller branches, clades 1a and 1b. Clade 1a is composed of representatives of Calothrix (IV.II), Scytonema (IV.I), Fischerella (V) and Chlorogloeopsis (V) and clade $1 \mathrm{~b}$ contains representatives of Nostoc (IV.I), 
Cylindrospermum (IV.I) and Chlorogloeopsis (V). In clade 1a, Fischerella strains PCC 7603, PCC 7414 and UTEX 1931 occur with Scytonema strains PCC 7814 and PCC 7110 and Calothrix strain PCC 7102 in an unresolved polytomy, with Fischerella strain PCC 1903 and Chlorogloeopsis strain PCC 6718 as sister. Clade $1 \mathrm{~b}$ contains Nostoc strains PCC 7120, PCC 6720 and PCC 7423, Cylindrospermum strain PCC 7604 and Chlorogloeopsis strain PCC 6912.

Clade 2 is composed of representatives of Calothrix, Nostoc, Anabaena (IV.I), Nodularia (IV.I), Cylindrospermum and Tolypothrix (IV.II), all of which are members of subsection IV. Calothrix strain PCC 7507 occurs with Nostoc commune UTEX 584; they are sister to Anabaena strains PCC 7122, PCC 7108 and ATCC 33047. Also occurring on clade 2 are Nodularia strains PCC 73104 and PCC 7804, Cylindrospermum strain PCC 7417 and Tolypothrix strain PCC 7101, which is located at the base of clade 2 . Additional parsimony and distance analyses of the data matrix resulted in trees that were virtually identical to that in Fig. 1 .

It has been suggested that classifications based on morphological and developmental features may not represent phylogenetic relationships within the heterocystous lineage, as some of the characters that have been used traditionally may be phenotypically plastic (Mollenhauer, 1988; Rippka, 1988; Rippka \& Herdman, 1992). This is exemplified by Nostoc strain PCC 7120, which was formerly considered to be a species of Anabaena (Lachance, 1981; Rippka, 1988; Rippka \& Herdman, 1992; Turner, 1997; Zehr et al., 1997; Tamas et al., 2000; Henson et al., 2002), and by Nostoc strain PCC 6720, which was once described as Anabaenaopsis (Rippka et al., 1979). The nifD phylogeny presented here supports the monophyly of the heterocystous cyanobacteria, which is congruent with $16 \mathrm{~S}$ rRNA phylogenies (Giovannoni et al., 1988; Wilmotte, 1994; Nelissen et al., 1996; Turner, 1997; Turner et al., 1999; Wilmotte \& Herdman, 2001; K. C. Kenyon, L. E. Watson \& S. R. Barnum, unpublished results), $23 \mathrm{~S}$ rRNA gene sequences (K. C. Kenyon, L. E. Watson \& S. R. Barnum, unpublished results) and partial nifH sequences (Zehr et al., 1997, 1998, 2000). However, nifD does not support the monophyly of subsection $\mathrm{V}$, which is congruent with nifH results (Zehr et al., 1997, 1998, 2000), but incongruent with 16S rRNA phylogenies. Although 16S rRNA data support division of the heterocystous cyanobacteria into subsections IV and V, their division is not strongly supported as being monophyletic (Wilmotte \& Herdman, 2001).

16S rRNA phylogenies support the monophyly of subsection $\mathrm{V}$ and its position as having arisen from within subsection IV (Giovannoni et al., 1988; Wilmotte, 1994; Nelissen et al., 1996; Turner, 1997; Turner et al., 1999; Wilmotte \& Herdman, 2001). Although subsections IV and V are still considered to be taxonomic divisions, Wilmotte \& Herdman (2001) suggested that their distinction is not reflective of evolutionary relationships within the heterocystous lineage. nifH phylogenies do support the monophyly of the heterocystous cyanobacteria, but they do not support the monophyly of subsection V; rather, members of subsection $\mathrm{V}$ are interspersed among members of subsection IV (Zehr et al., 1997, 1998, 2000).

Although nifD does not differentiate the members of subsections IV and V, it does support the hypothesis that ability to undergo cellular division in more than one plane (the single characteristic that separates subsection V from subsection IV) may have arisen more than once (Turner, 1997). Interestingly, a Nostoc (subsection IV) symbiont of the moss Blasia pusilla has been observed to undergo cellular division in multiple planes in culture (Gorelova et al., 1996), which raises the question of whether or not cellular division in one or more than one plane is a valid character for determining phylogenetic relationships.

nifD supports the monophyly of the heterocystous cyanobacteria. Our results failed to fully distinguish subsections IV and V, suggesting that their classification may not reflect phylogenetic relationships. Furthermore, the division of subsection IV into two distinct groups, IV.I and IV.II, based on whether or not their trichomes show basal-apical polarity, is not supported by nifD. Analysis of nifD is not congruent with morphological characters that are used to delineate the heterocystous cyanobacteria.

\section{Acknowledgements}

This research was partially funded by National Science FoundationPOWRE grant no. 9973340 to S. R. B., a Miami University Committee on Faculty Research grant to S. R. B., Ohio Sea Grant Development to S. R. B. and L. E. W. and an Ohio Board of Regents Academic Challenge grant to B. J.H. We also acknowledge the help of Chris Wood and The Center for Bioinformatics and Functional Genomics at Miami University and Eric Stahlberg with the Ohio Super Computer. This manuscript represents part of the thesis of the first author (B. J. H.) for an MS in Botany from Miami University.

\section{References}

Bremer, K. (1994). Branch support and tree stability. Cladistics 10, 295-304.

Castenholz, R. W. (1992). Species usage, concept, and evolution in the cyanobacteria (blue-green algae). J Phycol 28, 737-745.

Castenholz, R. W. (2001). Phylum BX. Cyanobacteria. In Bergey's Manual of Systematic Bacteriology, 2nd edn, vol. 1, pp. 473-487. Edited by D. R. Boone \& R. W. Castenholz. New York: Springer.

Castenholz, R. W. \& Waterbury, J. B. (1989). Group I. Cyanobacteria. In Bergey's Manual of Systematic Bacteriology, vol. 3, pp. 1710-1728. Edited by N. R. Krieg \& J. G. Holt. Baltimore: Williams \& Wilkins.

Felsenstein, J. (1985). Confidence limits on phylogenies: an approach using the bootstrap. Evolution 39, 783-791.

Giovannoni, S. J., Turner, S., Olsen, G. J., Barns, S., Lane, D. J. \& Pace, N. R. (1988). Evolutionary relationships among cyanobacteria and green chloroplasts. J Bacteriol 170, 3584-3592.

Golubic, S. (1976). Taxonomy of extant stromatolite building cyanophytes. In Stromatolites (Developments in Sedimentology no. 20), pp. 127-140. Edited by M. R. Walter. New York: Elsevier.

Gorelova, O. A., Baulina, O. I., Shchelmanova, A. G., Korzhenevskaya, T. G. \& Gusev, V. G. (1996). Heteromorphism of the cyanobacterium Nostoc sp., a microsymbiont of the Blasia 
pusilla moss. Microbiology (English translation of Mikrobiologiya) 65, 726-791.

Hayes, J. M. (1983). Geochemical evidence bearing on the origin of aerobiosis, a speculative interpretation. In Earth's Earliest Biosphere: its Origin and Evolution, pp. 291-301. Edited by J. W. Schopf. Princeton: Princeton University Press.

Henson, B. J., Watson, L. E. \& Barnum, S. R. (2002). Molecular differentiation of the heterocystous cyanobacteria, Nostoc and Anabaena, based on complete nifD sequences. Curr Microbiol 45, 161-164.

Henson, B. J., Watson, L. E. \& Barnum, S. R. (2004). The evolutionary history of nitrogen fixation, as assessed by nifD. J Mol Evol (in press).

Hoffmann, L. \& Castenholz, R. W. (2001). Subsection V. (Formerly Stigonematales Geitler 1925). In Bergey's Manual of Systematic Bacteriology, 2nd edn, vol. 1, pp. 589-599. Edited by D. R. Boone \& R. W. Castenholz. New York: Springer.

Huelsenbeck, J. P., Hillis, D. M. \& Jones, R. (1995). Parametric bootstrapping in molecular phylogenetics: applications and performance. In Molecular Zoology: Advances, Strategies and Protocols, pp. 19-45. Edited by J. D. Ferraris \& S. R. Palumbi. New York: Wiley.

Lachance, M.-A. (1981). Genetic relatedness of heterocystous cyanobacteria by deoxyribonucleic acid-deoxyribonucleic acid reassociation. Int J Syst Bacteriol 31, 139-147.

Maddison, D. R. \& Maddison, W. P. (2000). MacClade version 4.0. Sunderland, MA: Sinauer Associates.

Mathur, M. \& Tuli, R. (1990). Cluster analysis of genes for nitrogen fixation from several diazotrophs. J Genet 69, 67-78.

Mollenhauer, D. (1988). Nostoc species in the field. Arch Hydrobiol Suppl 80, 1-4.

Nelissen, B., De Baere, R., Wilmotte, A. \& De Wachter, R. (1996). Phylogenetic relationships of nonaxenic filamentous cyanobacterial strains based on 16S rRNA sequence analysis. J Mol Evol 42, 194-200.

Posada, D. \& Crandall, K. A. (1998). MODELTEST: testing the model of DNA substitution. Bioinformatics 14, 817-818.

Rippka, R. (1988). Recognition and identification of cyanobacteria. Methods Enzymol 167, 28-67.

Rippka, R. \& Herdman, H. (1992). Pasteur Culture Collection of Cyanobacteria: Catalogue and Taxonomic Handbook. I. Catalogue of Strains. Paris: Institut Pasteur.

Rippka, R., DeReuelles, J., Waterbury, J. B., Herdman, M. \& Stanier, R. Y. (1979). Generic assignments, strain histories and properties of pure cultures of cyanobacteria. J Gen Microbiol 111, 1-61.
Rippka, R., Castenholz, R. W. \& Herdman, M. (2001). Subsection IV. In Bergey's Manual of Systematic Bacteriology, 2nd edn, vol. 1, pp. 562589. Edited by D. R. Boone \& R. W. Castenholz. New York: Springer.

Schopf, J. W., Hayes, J. M. \& Walter, M. R. (1983). Evolution of Earth's earliest ecosystems: recent progress and unsolved problems. In Earth's Earliest Biosphere: its Origin and Evolution, pp. 361-384. Edited by J. Schopf. Princeton: Princeton University Press.

Sprent, J. \& Sprent, P. (1990). Nitrogen Fixing Organisms: Pure and Applied Aspects. New York: Chapman and Hall.

Swofford, D. L. (2002). PAUP*: Phylogenetic Analysis Using Parsimony (*and other methods), version 4.0. Sunderland, MA: Sinauer Associates.

Tamas, I., Svircev, Z. \& Andersson, S. (2000). Determinative value of a portion of the nifH sequence for the genera Nostoc and Anabaena (cyanobacteria). Curr Microbiol 41, 197-200.

Thiel, T. (1993). Characterization of genes for an alternative nitrogenase in the cyanobacterium Anabaena variabilis. $J$ Bacteriol 175, 6276-6286.

Thompson, J. D., Higgins, D. G. \& Gibson, T. J. (1994). CLUSTAL W: improving the sensitivity of progressive multiple sequence alignment through sequence weighting, position-specific gap penalties and weight matrix choice. Nucleic Acids Res 22, 4673-4680.

Turner, S. (1997). Molecular systematics of oxygenic photosynthetic bacteria. Plant Syst Evol Suppl 11, 13-52.

Turner, S., Pryer, K. M., Miao, V. P. \& Palmer, J. D. (1999). Investigating deep phylogenetic relationships among cyanobacteria and plastids by small subunit rRNA sequence analysis. $J$ Eukaryot Microbiol 46, 327-338.

Wilmotte, A. (1994). Molecular evolution and taxonomy of the cyanobacteria. In The Molecular Biology of Cyanobacteria, pp. 1-25. Edited by D. Bryant. Dordrecht, Netherlands: Kluwer.

Wilmotte, A. \& Herdman, M. (2001). Phylogenetic relationships among the cyanobacteria based on 16S rRNA sequences. In Bergey's Manual of Systematic Bacteriology, 2nd edn, vol. 1, pp. 487-493. Edited by D. R. Boone \& R. W. Castenholz. New York: Springer.

Zehr, J. P., Mellon, M. T. \& Hiorns, W. D. (1997). Phylogeny of cyanobacterial nifH genes: evolutionary implications and potential applications to natural assemblages. Microbiology 143, 1443-1450.

Zehr, J. P., Mellon, M. T. \& Zani, S. (1998). New nitrogen-fixing microorganisms detected in oligotrophic oceans by amplification of nitrogenase (nifH) genes. Appl Environ Microbiol 64, 3444-3450.

Zehr, J. P., Carpenter, E. J. \& Villareal, T. A. (2000). New perspectives on nitrogen-fixing microorganisms in tropical and subtropical oceans. Trends Microbiol 8, 68-73. 